\title{
O modelo político na Constituição Vigente.
}

\author{
Manoel Gonçalves Ferreira Filho \\ Professor Titular de Direito Constitucional na \\ Faculdade de Direito da Universidade de \\ São Paulo.
}

Das tradições desta Casa nenhuma é mais augusta que a do amor à Liberdade. Pela Liberdade jamais pouparam mestres e discípulos todos os sacrifícios; à causa da Liberdade sempre se votaram os momentos mais nobres e dignificantes da vida acadêmica.

$\mathrm{O}$ amor à Liberdade gera o apêgo à Democracia. E com toda a razão. Que valor mais alto informa a Democracia seıão a Liberdade?

Por isso, na abertura do ano acadêmico, não é sem propósito indagar da sorte da Democracia nas instituições brasileiras. Cabe cogitar do Modelo político na Constituição vigente, que é, precisamente, o tema da aula que ora se pronuncia.

\section{Constituição e modelo político.}

Toda Constituição configura um modelo político. $\mathrm{Na}$ medida em que define a fonte do Poder, estabelece os órgãos de governo, o modo de seleção de seus titulares, a extensão de sua competência, está ela fixando um modelo político.

No plano do Direito, porém, ao contrário do que sucede

* Aula inaugural do ano letivo, proferida na Faculdade de Direito da Universidade de São Paulo, em $1^{0}$ de março de 1972. 
no campo de outras ciências sociais, o modelo não é apenas um quadro, o quadro que espelha o desenvolvimento de um processo, oferecendo uma imagem exata, embora simplificada, da realidade. $\mathrm{Na}$ Constituição, o modelo é antes um projeto, o projeto de como há de desdobrar-se o processo político.

Entretanto, raramente, ou nunca, o projeto constitucional escapa, em sua prática diuturna, de deformações. Assim, o projeto, o desenho idealizado do processo, enseja propriamente o modelo, o quadro real de desdobramento do processo político. Desse modo, conquanto caiba a distinção entre projeto e modelo constitucional, o estudo conjunto de ambos, o estudo do modelo, lato sensu, é que verdadeiramente revela, em toda a sua riqueza, o impacto da Constituição no processo político.

\section{O projeto constitucional : a Democracia pelos partidos.}

A Constituição vigente procede de um movimento de inspiração democrática. Aspirava a Revolução de Março, na palavra de seu chefe, o Mal. Castello Branco, a "restaurar a legalidade, revigorar a democracia, restabelecer a paz e promover o progresso e a justiça social" (Discurso de 11 de abril de 1964) Decorria da necessidade de assegurar a sobrevivência das instituições democráticas, ameaçadas por um Governo que, embora legal em sua origem, se tornara ilegítimo por seus propósitos liberticidas.

Para consagrar os ideais e princípios da Revolução, garantindo a estabilidade política e assim estabelecendo bases seguras para a Democracia, é que se elaborou e promulgou a Constituição vigente. Esta não renega a sua inspiração. Solenemente reafirma, logo no art. $1 .^{\circ}$, o princípio democrático: "Todo poder emana do povo e em seu nome é exercido"

Está nesse princípio o alicerce fundamental do projeto constitucional brasileiro. Todo o poder emana do povo. Toda autoridade há de provir da escolha popular. 
A mais alta de todas as autoridades é, sem dúvida, o Presidente da República. Fiel às tradições republicanas, a Constituição manteve o presidencialismo que se caracteriza, politicamente e em primeiro lugar, pela preeminência do Presidente da República, ao mesmo tempo chefe de Estado e chefe do Governo.

Tal preeminência, inerente ao regime, ainda mais se acentua contemporaneamente, por força de fatores incoercíveis. Entre estes avultam a ampliação das atividades governamentais no domínio econômico e social, o intervencionismo, e a gravidade hodierna dos problemas de segurança, que, confiados ao Executivo, tendem a soerguê-lo em detrimento do Legislativo. Por outro lado, essa preponderância se agrava em razão do desprestígio dos parlamentos decorrente da ineficácia e da futilidade dos debates intermináveis, cujos meandros são incompatíveis com a velocidade da vida moderna.

A esses fatores, que são universais, socorrem outros que são especificamente brasileiros. De todos o mais flagrante é a inclinação para o poder pessoal. Esse personalismo está no cerne da concepção brasileira do presidencialismo. Formuloua claramente Campos Sales ao conceituar esse regime como o "governo pessoal constitucionalmente organizado" (Apud João Camilo de Oliveira Tôrres, O Presidencialismo no Brasil, O Cruzeiro, Rio de Janeiro, 1962, pág. 222) E, na verdade, como o ilustre paulista, sem dizê-lo embora, os Presidentes da República brasileira sempre se consideraram "o governo e não apenas o chefe do Governo" (Id., pág. 223) . Com essa colocação, aliás, perfeitamente se compadece a vida nacional, que tudo espera do Presidente.

$\mathrm{Na}$ Constituição vigente, a preeminência presidencial, diga-se de passagem, foi exacerbada, em virtude da centralização considerada necessária ao desenvolvimento e do autoritarismo julgado indispensável à estabilidade política.

Promana do que foi dito ser a eleição do Presidente da República a chave da estrutura política. Na medida em que 
sua escolha emanar do povo, estará o grau de Democracia realmente inscrito nas instituições.

Segundo a Constituição (art. 74 da redação estabelecida pela Emenda Constitucional n. ${ }^{\circ}$ 1, de 17 de outubro de 1969) , o Presidente da República será eleito pelo sufrágio de um colégio eleitoral, em sessão pública e mediante votação nominal. Esse colégio eleitoral, cuja composição e funçionamento deverão ser fixados em lei complementar ainda não elaborada, deverá compreender, por força do art. $74 \$ 1 .^{\circ}$ da Constituição, os membros do Congresso Nacional e delegados das Assembléias Legislativas dos Estados. Estes últimos em número fixado segundo o $\$ 2 .^{\circ}$ do referido artigo 74 , que dispõe: "Cada Assembléia indicará três delegados dentre seus membros e mais um por quinhentos mil eleitores inscritos no Estado, não podendo nenhuma representação ter menos de quatro delegados"

Adotou-se, portanto, a eleição indireta do Presidente da República. Tal solução não aberra do presidencialismo. Nos próprios Estados Unidos onde se inventou esse regime, a eleição presidencial não é direta. É ela feita por um colégio eleitoral, cujos membros, para tanto especialmente escolhidos, recebem mandato imperativo do corpo eleitoral, para votar neste ou naquele candidato. A eleição do Presidente dos Estados Unidos é, pois, semi-direta, já que o povo, ao escolher os componentes do colégio eleitoral, determina a votação deste, pois os membros do colégio eleitoral não são livres de votar em quem lhes aprouver mas têm, necessariamente, de votar no candidato indicado pelos que os elegeram.

No sistema adotado pela Constituição brasileira, a eleição presidencial pouco, ou nada, dependerá do corpo eleitoral. O colégio que escolherá o Presidente, é composto exclusivamente de parlamentares que, não raro, participarão da eleição ao findar-se de seus mandatos. De fato, isso ocorrerá em 1974, quando um terço dos senadores e todos os deputados federais e estaduais chamados a eleger o novo Presidente esta- 
rão no último ano de seus mandatos, separados, portanto, de seus eleitores há sete anos, até, para os senadores, há três anos para os deputados.

Por sua vez, só concorrerão, à Presidência candidatos designados por partidos políticos. Não contente com o monopólio das candidaturas que a legislação eleitoral concede aos partidos políticos, a Constituição, no art. 75 \$ $1 .^{\circ}$, timbrou em sublinhar que a disputa se travará entre candidatos registrados por partidos políticos. Entre estes, o colégio eleitoral deverá escolher o Presidente, nos dois primeiros escrutínios por maioria absoluta, no último, o terceiro, por maioria simples (art. $75 \& 20^{\circ}$ ).

O fato de o colégio eleitoral ser composto exclusivamente de parlamentares acresce a importância do modo de designação dos senadores e deputados federais e estaduais. De fato, esse ponto que já era de relevância por dizer respeito à composição do Legislativo, torna-se crucial quando dele depende a escolha do próprio Presidente da República.

Em face de preceitos constitucionais expressos, a eleição dos senadores se fará, pelo voto direto, pelo sistema majoritário simples, enquanto a dos deputados, tanto federais quanto estaduais, ainda pelo voto direto, mas pelo sistema de representação proporcional. Todos esses parlamentares serão forçosamente homens de partido. Só os partidos políticos podem, consoante se assinalou acima, indicar candidatos a eleições, candidatos que, segundo a legislação vigente, deverão estar a eles vinculados. Por outro lado, esses parlamentares estão obrigados, em decorrência de preceito constitucional expresso, à fidelidade partidária, sob perda do mandato (art. 152 \&único).

Infere-se do exposto que o modelo adotado repousa integralmente sobre os partidos. Entrega-lhes a seleção dos candidatos, seja à Presidência da República, seja às Câmaras e demais órgãos representativos. Obriga rigorosamente, ao me- 
nos os parlamentares, à estrita disciplina partidária. Desse modo, segundo o projeto constitucional, o Governo terá como chefe um homem de partido, eleito por homens de partido que constituirão as câmaras representativas.

Segue, portanto, o projeto institucionalizado a fórmula da Democracia pelos partidos.

Segundo esta, os partidos são essenciais à Democracia. São indispensáveis para que o povo possa governar-se verdadeiramente.

Na verdade, essa concepção parte de uma idéia que RousSEAU exprimiu, sarcasticamente embora, n'O Contrato Social. Ou seja, que não basta para um povo governar-se que ele escolha os seus governantes. Ironiza Rousseau: "O povo inglês pensa ser livre mas se engana; êle não o é senão ao eleger os membros do parlamento: logo que estes estão eleitos, é êle escravo, não é nada. Nos curtos momentos de sua liberdade, o uso que faz dela, faz com que mereça realmente perdê-la" (Livro III, Cap. XV)

Se o povo, ao eleger os governantes, dá a estes carta branca, não estabelece diretrizes seguras que seus representantes devam rigorosamente seguir, estará ele sujeitando-se inteiramente ao poder alheio. Na realidade dos fatos, quem governa serão os representantes, reduzindo-se a aparente Democracia a um verdadeiro despotismo dos eleitos.

Para fugir a essa situação, raciocina a doutrina da Democracia pelos partidos, o caminho é dar aos partidos políticos uma função constitucional, da qual lhes resulta um status especial, com direitos e deveres particulares. Os partidos devem incumbir-se de preparar programas de governo e de selecionar homens que se disponham a executar fielmente esses programas. Assim, votando em partidos, o povo estará optando ao mesmo tempo por um programa e por um governo, estará elegendo um governo que, cumprindo um programa determinado, estará governando segundo a vontade popular. Desse 
modo, a eleição não se esgotará na seleção de governantes do povo mas terá o sentido de designação de mandatários do povo.

Coerente com essa concepção, a Constituição brasileira cuidou de estabelecer as bases de um estatuto dos partidos políticos (art. 152) que visa a dar-lhes estrutura democrática, disciplina interna e fidelidade programática. Esse estatuto, hoje estabelecido pela Lei n. ${ }^{0} 5.862$, de 21 de julho de 1982 , complementa o projeto político estabelecido, do qual é parte fundamental.

\section{O modelo constitucional: a oligarquia dos políticos.}

Por motivos que é desnecessário analisar no momento, o projeto que a Constituição desenha, não foi ainda realmente posto a prova. E é bom que nunca o seja. De fato, em seu idealismo ingênuo, esse projeto enseja o estabelecimento de um modelo não democrático, verdadeiramente oligárquico, de governo.

O esquema da Democracia pelos partidos é uma teorização do processo político britanico. $\mathrm{Na}$ Grã-Bretanha, com efeito, dois partidos apenas, razoavelmente disciplinados, dotados de programas mais ou menos definidos, é que verdadeiramente disputam as eleições. Daí decorre que a eleição popular importa numa opção entre dois programas da qual resulta a escolha entre duas equipes governamentais. Lá, porém, a disputa que noutros países se radicalizaria, em virtude do espírito peculiar ao povo inglês se amortece, perdendo as arestas mais agudas. Basta salientar dois aspectos desse espírito: a tolerância e o fairplay, termo que de tão britanico não tolera tradução.

Tolerância. Só um povo tolerante aceita, tranquilamente, que ora prevaleça uma orientação política, ora outra, sem se entredevorar numa luta fratricida. Para aceitar essa alter nância, apenas um povo cujos membros admitam, sem passionalismo, que possam estar errados, estando certos os seus 
opositores. Fairplay. Esssa alternância de partidos monolíticos só é possível, sem prejuízos seríssimos para a administração pública, se cada um for capaz de respeitar a obra do outro, se cada um não quiser fazer tábua rasa de todo o trabalho do anterior.

Bastaria a ausência dessas duas qualidades para desaconselhar para um povo qualquer a fórmula britanica de Democracia. A análise da Democracia pelos partidos, porém, revela a delicadeza de seu mecanismo e, conseqüentemente, a improbabilidade de seu transplante.

Em primeiro lugar, essa fórmula só é adequada quando encontra respaldo no bipartidismo. Se houver apenas dois partidos em disputa, ou, o que dá no mesmo, só dois partidos reunirem condições para aceder ao Poder. Realmente o povo ao votar nas eleições opta por um programa e, portanto, por um governo e uma orientação definida. Havendo multiplicidade partidária, a opção é inviável, não é mais significativa.

De fato, havendo multiplicidade partidária, segundo ensina a experiência, dificilmente um partido isolado conseguirá a maioria. Nessas condições, o Governo resultará certamente de uma coligação, o que importa sempre no sacrifício da clareza programática. Dependendo de uma soma de partidos, as decisões políticas, mormente as legislativas, serão resultado não da vontade do povo mas do acordo entre os representantes, segundo combinações de interesses à sombra dos bastidores.

Essa condição, o bipartidismo, apresenta atualmente o Brasil, na aparência. Dissolvidos os antigos partidos, restam hoje frente a frente a Arena e o $\mathrm{MDB}$, não tendo sido criado, nem sendo provável que consiga preencher as dificeis requisitos da lei, qualquer terceiro partido.

Entretanto, os partidos brasileiros não estão à altura da missão que a Democracia pelos partidos lhes impõe. Não passam de conglomerados, decorrentes de exigências eleitorais, 
sem programa definido e, o que é muito pior, sem vida própria. Apesar das prescrições legais que desejam uma estruturação partidária autêntica, vinda de baixo para cima, com intensa participação popular, permanecem eles vazios, como corpos sem alma.

A autenticidade dos partidos é outra das condições da Democracia pelos partidos. No Brasil, essa autenticidade parece ser, em face da experiência do passado e do presente, um sonho remoto, utópico. Traço inegável do caráter nacional brasileiro é a falta de inclinação para a vida cívica e associativa.

Esse traço não é de hoje, nem é fruto de circunstâncias excepcionais. Através dos tempos, vem sendo notado por observadores seguros da realidade brasileira. Já na História do Brasil de Frei Vicente do Salvador encontra-se a seguinte observação "nem um homem nesta terra é repúblico, nem zela ou trata do bem comum, senão cada um do bem particular" (Apud Evaristo de Morais Filho, Uma possível nota do caráter brasileiro, em Carta Mensal, Rio de Janeiro, julho de 1971, ano XVI, n. ${ }^{0}$ 196, pág. 22) A mesma observação faz Capistrano de Abreu (Id., pág. 19) Dela não discrepa OliveIRA Viana que assinala: "As formas de solidariedade voluntária, de cooperação espontânea e livre, só aparecem entre nós sob a ação empolgante dos grandes entusiasmos coletivos: a frio, com a automaticidade instintiva dos anglo-saxões não as criamos, nem as sustentamos nunca. Partidos políticos ou ligas humanitárias, sociedades de fins morais ou clubes recreativos, todas essas várias formas de solidariedade têm entre nós uma vida artificial e uma duração efêmera" E acrescenta mais além: "Normalmente, o círculo da nossa simpatia ativa não vai, com efeito, além da solidariedade de clan. É a única forma de solidariedade social que realmente sentimos, é a única que realmente praticamos" (Id., pág. 19/20)

Desse modo, é improvável a participação ativa, constante e intensa, do brasileiro na vida partidária. Ora, sem essa par- 
ticipação, os partidos nacionais tenderão forçosamente a se tornar oligárquicos e, mais do que isso, instrumentos de oligarquias.

Se oligárquicos, os partidos deformarão completamente o sistema. Dominados por pequenos grupos, servirão eles, sobretudo, para propiciar uma influência desmedida aos militantes que os controlam. Esses políticos, por assenhorearem-se da máquina partidária, poderão a seu bel prazer e segundo seus interesses, raramente coincidentes com o interesse comum, escolher candidatos, predeterminando forçosamente a escolha popular, impor diretrizes cujo cumprimento a fidelidade partidária tornará obrigatórias.

Por outro lado, a Democracia pelos partidos pressupõe programas partidários definidos. Definidos não em termos ideológicos mas em diretrizes precisas que sirvam para a orientação do Governo. Se as linhas programáticas forem vagas e fugidias, de modo algum o Governo estará adstrito a uma orientação precisa, aprovada pelo povo, como é da índole do sistema.

Este empecilho é talvez insuperável. Disputando os votos em grupos secundários, cujos membros não sentem os mesmos problemas, ou, ao menos, não os encaram do mesmo ângulo, os partidos tendem a reduzir seus programas a generalidades, a fórmulas atraentes e vagas, para tentar seduzir o maior número, sem ferir, se possível, a ninguém. Os problemas concretos são evitados, porque dividem. Ou então são tratados em fórmulas obscuras que permitam uma interpretação adequada a cada auditório. Disso decorre que a opinião pública se aglutina em torno de problemas irreais ou meramente ideológicos. Assim, a opção popular não encontra jamais nos programas a indicação segura dos passos que haverão de ser dados se o partido triunfar e assumir o Governo Nas socieclades industriais, sendo os interesses dos indivíduos demasiado diversos e freqüentemente conflitantes, a luta política tende a se travar em torno de problemas gerais que de algum 
modo tocam a todos. Ou, como observa JACQUES LAMBERT, tende a por em primeiro plano "as ideologias e as questões de princípio", porque sobre estas "é mais fácil oferecer às opiniões uma opção da qual resulte uma maioria e uma minoria" (Structure Sociale et Opinion Publique, em L'Opinion Publique, Puf, Paris, 1957, pág. ${ }^{85}$ )

\section{Democracia para o Brasil.}

O cumprimento rigoroso das normas constitucionais não fará do Brasil uma verdadeira Democracia. Essa é a triste lição que deflui inexoravelmente do estudo acima feito.

O projeto constitucional desconheceu a realidade pátria, não levou em conta o caráter do povo que há de vivificar as instituições, nem, como não seria dificil demonstrar , as suas condições sociais e econômicas. O Brasil não tem partidos autênticos. Provavelmente jamais escapará de partidos artificiais, controlados por oligarquias ou a serviço de minorias.

Na prática, esse projeto conduzirá a um modelo em que o Poder pertencerá às cúpulas partidárias. Será usado segundo os interesses de homens de partido, a fim de atender a preocupações, nem sempre condizentes com o interesse geral.

A Constituição vigente desserve os propósitos salutares da Revolução de Março. Aplicada fielmente, não provocará o revigoramento da Democracia mas sim, em grau muito pior, a corrupção, a desordem, a subversão, a demagogia do período imediatamente anterior a 31 de março de 1964.

A inconveniência do modelo político da Constituição não é desconhecida. Muitos não a apontam porque a consideram uma fórmula ideal que o povo brasileiro poderá praticar, um dia, quando for suficientemente rico, esclarecido e amadurecido. Enquanto esse dia não chega, aceitam silenciosamente que o processo político se desenrole ao arrepio da Constituição. Outros temem que, ao acusá-la, se vejam confundidos 
com saudosistas ou com os subversivos, ambos verdadeiros inimigos da Democracia.

Ao contrário. A causa da Democracia coincide com o ideário em nome do qual se fez a Revolução. Aquela e esta reclamam a reforma da Constituição, para a instauração de um modelo apto a realizar verdadeiramente a Democracia no Brasil.

Claro está que não é êste o momento próprio para essa reforma. Faltam idéias maduras a indicar rumos novos, a sugerir soluções que, sem menosprezar a experiência estrangeira, levem em conta, em primeiro lugar e acima de tudo, as condições nacionais. É preciso convir, porém, que essas idéias jamais amadurecerão se não forem cultivadas pelo debate, mas pelo debate adulto e responsável.

Esse debate, contudo, não dispensa uma obra urgente, cuja necessidade avulta independentemente deste ou daquele modelo político. Cumpre promover, tão aceleradamente quanto o desenvolvimento econômico, o desenvolvimento político do povo brasileiro. E impossível que um povo desprovido de formação política possa bem governar-se, conquanto não seja possível que um povo possa aprender a governar-se sem experimentá-lo. Igualmente, importa suscitar uma nova elite política que substitua a que estiver gasta ou desmoralizada. Sem formação política do povo, sem elite política democrática, as instituições mais perfeitas darão maus frutos.

A causa da Democracia é a causa da Liberdade. Não há causa mais nobre para esta Faculdade de Direito. 